\title{
PREOPERATIVE DIGITALIZATION. A METHOD TO REDUCE POSTOPERATIVE COMPLICATIONS*
}

By Samuel H. Geist, M.D., F.A.C.S., and JosePh S. Somberg, M.D., New YORK CITY

DOSTOPERATIVE complications, especially those involving the respiratory tract have always caused the surgeon considerable anxiety. In spite of improvements in the methods of administering anesthesia, careful pre- and postoperative care, the refinement of operative technic and the rapidity of operative procedures, we have been apparently unable to reduce the number of such cases materially.

Cutler, working with Worton and Hunt, and. Whipple, who have done considerable work recently, especially with the purpose of limiting these pulmonary complications, have not been able to reduce the incidence of these serious postoperative effects to any great degree.

One may for purposes of classification group postoperative complications under two large headings,- vascular and nonvascular. Under vascular complications, the pulmonary group are most important. Pulmonary complications in almost all instances are dependent on postoperative vascular conditions. We are all familiar with the so-called hypostatic pneumonia either terminal or in the course of some chronic disease. This condition is due entirely to circulatory stasis, with poor aeration, on which is superimposed an infection. Pulmonary edema is another well recegnized postoperative lesion of vascular origin.

Polak haș recently studied the importance of maintaining the blood pressure in operative conditions. The pressure, especially the pulse pressure, he feels, is an important factor in determining the postoperative course of the patient.

His curve (average) is given in Fig. 1. The average drop in pressure (postoperative) at the end of one hour was $14.2 \mathrm{~mm}$. The return to normal was usually accomplished in 24 hours.

A. H. Miller notes the same fall in pressure immediately following operation. In our series we have carried on readings similar to Polak, with practically complete parallelism. In one case, however, where the preoperative pressure was 220 systolic, 180 diastolic, with evidences of marked nephritic changes, the pressure dropped to 110 and then gradually rose to 140 on the day following operation. In six days the pressure was practically at the prenperative level of 220 . We all have noted the fall in pressure following operation, due usually

\footnotetext{
*Presented at a meeting of the New York Obstetrical Society, April 14, 1922.
} 
to diminution of cardiac efficiency, and it is this fall in pressure that results in stasis in the smaller arterial and venous radicles. The first 24 hours after operation, in all probability, determine to a great extent, the pneumonic or other vascular complications. We have mentioned the so-called hypostatic pneumonia and we feel that practically all postoperative pneumonitis has an analogous etiology. The other pulmonary complications, embolism or thrombosis may be grouped under vaseular lesions but just how much they are influenced by a maintenance of the pressure level can only be judged after observations on a very large series of cases. Phlebitis is occasionally due to trauma during the operation, but usually it is due to stasis and infec-

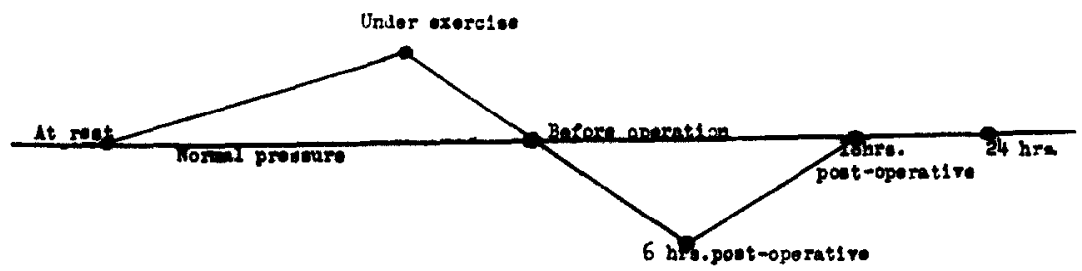

Fig. 1.-Mlood pressure curve ustually seen in operatives. (Polak's curve, undigitalized curve.)

tion and it too may react favorably to an improvement in the eardioraseular activity. Postoperative shock is still an unsolved problem, but we know that there is a marked fall in pressure in these cases of shock, just as in other postoperative conditions. If the pressure ean be maintained either partially or totally, the shock will be very much

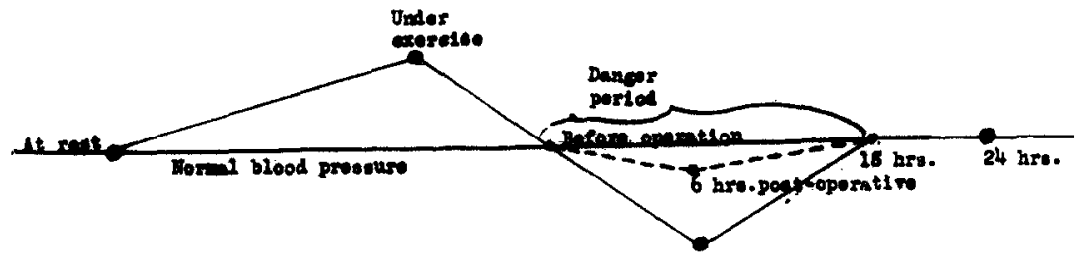

Fig. 2.-Comparison of digitalized and undigitalized postoperative blood pressures. Note comparatively negligible drop during danger period in digitalized cases. Digitalized. Undigitalized.

lessened. The asthenia seen following operations, where there is no source of septic absorption, is always associated with a low pressure, but here cause and effect must be closely differentiated.

With the above in view it is reasonable to assume that any measure which will help to maintain the pressure, and especially the pulse pressure, would also be of value in reducing the incidence of the complications dependent on vaseular disturbances. We decided that digitalis, or any of its derivatives, being powerful cardiac stimulants would be of value, and a series of operative cases was investigated to determine the value. These cases were grouped in three divisions. 
In one division the cases were digitalized by a method that we termed the "rapid method." The tincture of digitalis (standardized) was given as follows: 0.15 c.c. per lb. of body weight of patient was the total amount used. One-half of this was given 24 hours before operation, one-fourth six hours later, and the remainder six hours after the second dose. The pressure and electrocardiogram was taken on the morning of the operation, the pulse rate and quality and general condition also being noted. The cases used were picked at random and usually the poorer operative risks were selected for digitalization.

The method of standardization was by the so-called "cat unit" method of Eggleston. By cat unit is meant the amount of a digitalis preparation "necessary to kill one kilogram of cat" when injected intravenously slowly and continuously. This is expressed in milligrams of the preparation. Experimentally 0.148 "cat unit" per pound is necessary for full digitalization.

In addition to the rapid method there were two other groups, one digitalized by the "slow method" to be described later and a control group.

The method of selection was quite arbitrary. Cases were picked at random for all three groups with a tendency however to relegate the poor risks to the groups for digitalization. In other words the controls were run under similar circumstances in every respect,-anesthetist, anesthesia, operating room temperature, technic, etc.

The second method of digitalization, the slow one mentioned above, was less heroic. The dosage was smaller, and a preparation other than the tincture was used. Digitan in one and one-half grain doses was given by mouth every two hours for six doses eommencing 24 hours before operation. On the morning of operation two more such doses were given. In comparing the two methods we feel that there is much to be said for both, but for general routine work the second is probably the better. Similar results were obtained by each method but there was less tendency towards digitalis nausea and vomiting with the slow method of administration. The doses were also smaller and the exhibition of the drug much easier. One and one-half grain of digitan equals 15 c.c. of the standardized tincture.

To determine the action of the digitalis on these apparently normal hearts, two methods were used, the electrocardiograph and the pulse rate. We can fully agree with White and Sattler who found that increased conduction time was a very important indicator of complete digitalization. The earliest indication of digitalis action however was the decrease of the amplitude of the T-wave in all leads, going on to reversal or inversion of the T-wave when complete digitalization is obtained. The blood pressure was uninfluenced. The pulse rate showed no appreciable change in the cases with normal hearts. The 
electrocardiograph was usually taken about two hours before operation. The blood pressure readings were taken on admission, ante- and postoperatively, at 6,12 and 24 hours to conform to Polak's technic for comparison.

The types of cases operated upon embraced practically all of the more severe gynecological and general surgical procedures. We attempted to use only the more severe eases, i.e., those requiring laparotomy, for digitalization. Using the "rapid method" we digitalized 27 cases.

TABLE I

Types of Cases Digitalized by "Rapid Method"

\begin{tabular}{|c|c|c|}
\hline & Hysterectomy & 10 \\
\hline & Ectopic & 2 \\
\hline & Plastic, interposition & 1 \\
\hline & Cervical amputation (very poor risk) & $\ddot{1}$ \\
\hline & Myomectomy and ventrofixation & 1 \\
\hline & Curettage (cardiac and tbe.) & 1 \\
\hline & Ovarian tumor & 1 \\
\hline & Diseased adnexa & 1 \\
\hline & Plastic, ventrofixation and Iigation of tubes & 1 \\
\hline & Cholecystectomy & 4 \\
\hline & Thoracotomy & 2 \\
\hline & Nephrectomy & 3 \\
\hline
\end{tabular}

Among these the anteoperative condition was good in fourteen, fair in three and poor in ten, due to cardiac conditions, emaciation, myocarditis, emphysema, bronchitis and associated lesions. The anesthesia (gas and ether) was uneventful in all the cases. The immediate postoperative examination showed good, full, slow, regular pulses. The color remained good in all except in one instance where there was a previous cmphysema and bronchitis. In 58 per cent of these cases there was no immediate postoperative vomiting or nausea. In 23 per cent there was nausea and in 19 per cent only was there vomiting. Of these one case showed true digitalis vomiting, the others were so-called "anesthesia vomiting." Very interesting was a delayed reaction seen in about 30 per cent. In this group vomiting occurring once or twice on the second and third day; in all probability this was a digitalis effect. All the possible causes of postoperative vomiting, such as gastric dilatation, etc., were ruled out. All of the digitalized cases regained their consciousness with complete orientation and very rapidly. Few showed the mental aberration seen so commonly. The postoperative recovery was unusually rapid.

The blood pressure was studied carefully on a majority of these cases. The postoperative drops averaged only $3 \mathrm{~mm}$. within the first 12 hours; after that the tension became normal.

The complications in this group were limited to one case of bronchitis which was of two days' duration and was probably a direct 
ether result. There were none of the severe pulmonary complications or vascular lesions that one encounters in a group of operated cases.

Forty-two cases were digitalized by the slower method using digitan gr. $1 \frac{1}{2}$ every two hours for 6 doses, commencing 24 hours before operation and giving two additional doses in the morning of the operation.

TABLe II

Types of Cases Digitalized by "Slow Method",

\begin{tabular}{lr}
\hline Hysterectomy & 15 \\
Plastic, etc. & 1 \\
Plastic and Moseheowitz operation & 1 \\
Diseased adnexa... & 1 \\
Therapeutic hysterotomy & 1 \\
Alexander (poor risk) & 1 \\
Ovarian eyst. & 2 \\
Appendectomy . & 1 \\
Myomectomy, bilateral salpingo-oophorectomy & 2 \\
Thorocotomy & 8 \\
Cholecystectomy and exploratories & 6 \\
Nephrectomy & 3 \\
\hline
\end{tabular}

Of these forty-two, eight were in very poor general condition: hypertension with renal disease and myocarditis, tuberculosis, mild uremia (nephrectomy 10 years ago) and asthenia. Postoperative the pulse was excellent in all cases except the one who had a hypertension and a myocarditis with a preoperative pressure of 220 . In this case the pulse was slightly irregular but it was of fair quality. This case also had an immediate postoperative drop of pressure to 110 which gradually rose to the preoperative level after a few days. The color was good in all the cases. In 63 per cent there was no vomiting; 24 per cent had the usual ether vomiting and 13 per cent had only nausea. One case showed vomiting in small amounts for three days. There was a delayed reaction in 15 per cent of the cases i.e., vomited two or three days later, probably a digitalis effect. The average drop of pressure in these cases was $5 \mathrm{~mm}$. These cases also showed electrocardiographic evidence of complete digitalization even though the total amount of digitalis was much less than that exhibited by the first method. The complications in this group consisted of one case of bronchitis lasting one day, probably irritative in cause.

We can sum up these two groups by saying that there were practically no complications. The postoperative course was excellent and there were no pronounced ill effects from the digitalis. The blood pressure drops were minimal, the pulse pressure being maintained throughout:

There were thirty-nine undigitalized eases, all in good condition before operation except three.

One of these three had a myocardial weakening, one was asthenic 


\begin{tabular}{|c|c|c|}
\hline UNDIGITALIZED & & COMPHICATIONS \\
\hline Hysterectomy & 11 & 1 pneumonia, 1 shoek \\
\hline Ovarian eyst & 1 & \\
\hline Plastic & 7 & 1 pneumonia antl 1 phlebitis \\
\hline Partial bilat. oophorectomy & 1 & \\
\hline Retained placenta & 1 & \\
\hline Eetopic & 1 & 1 shock \\
\hline Hysterotomy & 1 & \\
\hline Amp. of cervix, ligation of tulies & 1 & \\
\hline Alexander-appendectony & 1 & Bronelutis \\
\hline Plastic on tubes & 1 & I3ronehitis \\
\hline Appendectomy & 1 & \\
\hline Explor. lap. & 1 & \\
\hline Carcinoma fundus & 1 & \\
\hline Hermia (local) & 1 & 1 pneumonia \\
\hline Appendices (acuto) & 3 & 1 pneumonia \\
\hline (Molecystectony & ; & 1 pneumnnia \\
\hline Nephrectomy & 3 & $\begin{array}{l}1 \text { pneumonia-suppurative } \\
\text { bronchitis. }\end{array}$ \\
\hline
\end{tabular}

and the other was anemic. Postoperatively, $30 \mathrm{per}$ cent of these had a poor pulse; two cases developed such a poor, weak, irregular pulse that hypodermie stimulation with a digitalis preparation had to be used. Fifteen per cent showed poor color, either pallor or cyanosis. Fiffy-seven per cent vomited several times; 43 per cent did not vomit or had only nausea. The alertness seen in the digitalized cases was lacking, instead the usual postanesthetic mental aberration was the rule. The rapid recovery seen in the digitalized cases was also missing in the greater portion, and the asthenic condition of some of the patients was quite striking, when compared to the digitalized cases, who had had similar operative procedures. The average pressure drop was $14 \mathrm{~mm}$. taken at intervals of 6,12 , and 24 hours postoperatively. compared to the 3 and $5 \mathrm{~mm}$. drop of the digitalis cases. This curve parallels the one obtained by Polak and shown above.

The most interesting facts are presented by a perusal of the complications.

TABLE IV

ComplicatToNs

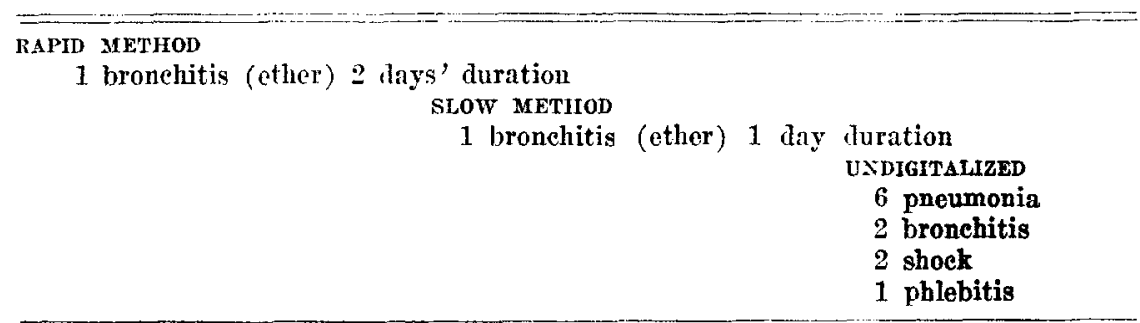

There were six cases of pneumonia, the diagnosis corroborated by the attending physician, a total of 15 per cent, two eases of shock, 
two cases of bronchitis and one case of phlebitis. The total percentage of complications is 27 per cent in these undigitalized cases, compared to the zero percentage of complications if one excludes the two very mild bronchitis eases seen in the digitalized groups. This is the most important and the outstanding feature of this series of experiments.

With the above in mind a careful search of the literature was made, but in no case were we able to find any reference to methodical digitalization with the possible exception of Mandl's work. Using an intramuscular injection of a digitalis preparation in comparatively small doses, he was able to obtain a reduction of postoperative complication from 27 per cent to 8 per cent. Whipple used the tincture preoperatively, but the doses were quite small and the tincture was apparently not standardized.

Lilienthal in an editorial article published in the International Journal of Surgery in 1907, suggested the administration of digitalis or strophanthin 24 hours before operation, in nervous persons, even if they have sound hearts; and in an article published in the Annals of Surgery for March, 1922, he states, (p. 259) in diseussing cases of poor surgical risk for lung resections, that "In any event digitalization should be aceomplished the 48 hours preceding operation."

Summing up the observations made in the three groups of cases we must be impressed by the fact that in the digitalized eases the pulmonary complications have been definitely lower, that other annoying and at times serious complications have also been minimized and that the method used to obtain these results is free from danger to the patient and is easy of administration.

Of the two methods of digitalization it seems that the slower method, using digitan, has the advantage of ease of application and also is less likely to produce even temporary, umpleasant digitalis effects.

\section{REFERENCES}

Cutler and Morton: Surg. Gynee. and Obst., 1917, xxv, 621. Culler and Hunt: Arch. Surg., 1920, i, 114. Whipple: Surg., Gynec. and Obst., 1918, xxvi, 29. Polak: Am. Jour. Obst., 1919, lxxx, 113. Miller: Jour. Am. Med. Assn., Feb., 1921. White and Sattler: Jour. Fxper. Med., 1911, xxxiii, 617. Mandt: Wion. Klin. Wehnschr., 1921, xviii, 34. 